\title{
The effects of peppermint on exercise performance
}

\author{
Abbas Meamarbashi ${ }^{*}$ and Ali Rajabi
}

\begin{abstract}
Background: Enhancing athletic performance is a great desire among the athletes, coaches and researchers. Mint is one of the most famous natural herbs used for its analgesic, anti-inflammatory, antispasmodic, antioxidant, and vasoconstrictor effects. Even though inhaling mint aroma in athletes has been investigated, there were no significant effects on the exercise performance.

Methods: Twelve healthy male students every day consumed one $500 \mathrm{ml}$ bottle of mineral water, containing $0.05 \mathrm{ml}$ peppermint essential oil for ten days. Blood pressure, heart rate, and spirometry parameters including forced vital capacity (FVC), peak expiratory flow rate (PEF), and peak inspiratory flow (PIF) were determined one day before, and after the supplementation period. Participants underwent a treadmill-based exercise test with metabolic gas analysis and ventilation measurement using the Bruce protocol.

Results: The FVC ( $4.57 \pm 0.90$ vs. $4.79 \pm 0.84 ; p<0.001)$, PEF ( $8.50 \pm 0.94$ vs. $8.87 \pm 0.92 ; p<0.01)$, and PIF $(5.71 \pm 1.16$ vs. $6.58 \pm 1.08 ; p<0.005)$ significantly changed after ten days of supplementation. Exercise performance evaluated by time to exhaustion ( $664.5 \pm 114.2$ vs. $830.2 \pm 129.8 \mathrm{~s})$, work (78.34 $\pm 32.84 \mathrm{vs} .118 .7 \pm 47.38 \mathrm{KJ})$, and power $(114.3$ \pm 24.24 vs. $139.4 \pm 27.80 \mathrm{KW}$ ) significantly increased ( $p<0.001)$. In addition, the results of respiratory gas analysis exhibited significant differences in $\mathrm{VO}_{2}(2.74 \pm 0.40$ vs. $3.03 \pm 0.351 \mathrm{~L} / \mathrm{min} ; \mathrm{p}<0.001)$, and $\mathrm{VCO}_{2}(3.08 \pm 0.47 \mathrm{vs} .3 .73$ $\pm 0.518 \mathrm{~L} / \mathrm{min} ; \mathrm{p}<0.001)$.

Conclusions: The results of the experiment support the effectiveness of peppermint essential oil on the exercise performance, gas analysis, spirometry parameters, blood pressure, and respiratory rate in the young male students. Relaxation of bronchial smooth muscles, increase in the ventilation and brain oxygen concentration, and decrease in the blood lactate level are the most plausible explanations.
\end{abstract}

Keywords: Peppermint essential oil, Exercise performance, Respiratory gas analysis, Spirometry

\section{Background}

Until now, many researches have been done on the effectiveness of various kinds of natural products in the improvement of sport performances. Mint (mentha) is a herb which is well known for its antispasmodic, painkilling [1-3], anti-inflammatory, antispasmodic, decongestant, and antioxidant effects [4]. Peppermint is one of the mentha species (i.e., mentha piperita, peppermint oil, mentha arvensis, cornmint oil) [5]. Menthol (29\%) and menthone (20-30\%) are the major components of the peppermint essential oil.

\footnotetext{
* Correspondence: a_meamarbashi@yahoo.com

Department of Physical Education and Sports Sciences, University of Mohaghegh Ardabili, Ardabil 56199-11367, Iran
}

External application of peppermint extract raised the pain threshold in human [6]. Peppermint aroma was also effective on perceived physical workload, temporal workload, effort, and anxiety [7]. Another research demonstrated the effectiveness of peppermint aroma administered through the nose or by mouth on the augmenting cognitive performance [8]. Peppermint aroma caused improvement on the tasks related to attentional processes, virtual recognition memory, working memory, and visual-motor response [8]. Moreover, peppermint aroma improved the typing performance [9]. In a study under four conditions (peppermint, jasmine, dimethyl sulfide, or a non-odorous), athletes performed a 15-minute treadmill exercise stress test, then mood and exercise performance were evaluated
C Biomed Central

(c) 2013 Meamarbashi and Rajabi; licensee BioMed Central Ltd. This is an Open Access article distributed under the terms of the Creative Commons Attribution License (http://creativecommons.org/licenses/by/2.0), which permits unrestricted use, distribution, and reproduction in any medium, provided the original work is properly cited. 
[10]. Perceived physical workload, temporal workload, and self-evaluated performance reported to have a significant difference in peppermint group. In an animal study, intraperitoneal injection of different components of peppermint into mice, significantly increased the ambulatory activity. Therefore, author suggested peppermint components are serving as a central nervous system stimulant [11].

The effect of supplementation with oral peppermint extract was also studied on the perceived lower leg muscular pain and blood lactate levels one hour before a 400-m running test [12]. In this study, the peppermint had a significant effect on the blood lactate level, but not on the muscle pain. Besides, the combination of peppermint oil and ethanol [13] reported to have a significant analgesic effect.

Using a Peak Flow Meter device showed an improvement in the lung capacity and inhalation ability after inhalation of peppermint aroma [14]. After inhalation of peppermint aroma, the nasal airflow force increased, thus the author speculated this effect supply more oxygen to the brain, which could be effective for continuing physical performance. On the other hand, menthol the main component of the peppermint essential oil investigated in a four-week randomised, placebo-controlled study on 23 patients with chronic asthma. Menthol group shown no significant differences in the vital capacity, forced expiratory volume or change in the peak expiratory flow rate [15]. Moreover, previous study on the athletic performance by using peppermint essential oil had no significant effect on the blood oxygen saturation, pulse rate, blood pressure, and mean arterial pressure (MAP) [16].

The possible ergogenic effect of aromas, has certainly received much publicity in recent years. However, there is very little scientific evidence to support or refute the claims made by merchants, practitioners, and manufacturers [17]. Hence, due to equivocal findings and lack of good-quality evidences on the effectiveness of peppermint essential oil in the exercise performance, the aim of this study was to assess the effects of oral supplementation with peppermint essential oil on the exercise performance, physiological and respiratory parameters.

\section{Methods}

\section{Subjects and study design}

Twelve (12) healthy male university students $\left(\mathrm{M}_{\mathrm{age}}=\right.$ $25.9 \pm 1.38 \mathrm{yrs} ; M_{\text {weight }}=69.9 \pm 5.58 \mathrm{~kg} ; M_{\text {height }}=177.0 \pm$ $4.2 \mathrm{~cm}$ ) randomly selected among 40 volunteers to take part in a quasi experiment by using the one-group pretest, post-test design. Participants tested before, and after ten days of peppermint essential oil consumption. Ethical approval to conduct this study obtained from the University Human Ethics Committee.

\section{Methodology}

All participants signed a consent form. The subjects were familiarized with the laboratory setting and the measurement techniques two days before the study. Blood pressure, breath rate, and resting heart rate were recorded. The chest circumference was measured by placing the flexible measuring tape around the chest at the level of the xipho-sternal junction. Pulmonary function tests performed using a handheld electronic turbine spirometer (Microlab spirometer, Micro Medical Limited of Rochester, England) and the best of three forced efforts such as forced vital capacity (FVC), peak expiratory flow rate (PEF), and peak inspiratory flow (PIF) were recorded.

Finally, participants underwent a standard treadmill exercise test (Bruce protocol), controlled by a computer program. A heart rate transmitter belt (Polar, Polar Electro, Finland) was attached to the chest to transmit the heart rate signals to the receiver. Respiratory gas and ventilation were measured with calibrated PowerCube Gas Analyzer (Ganshorn Medizin Electronic GmbH, Nie derlauer, Germany). Gas exchange variables including: oxygen uptake $(\mathrm{L} / \mathrm{min})$, carbon dioxide production $(\mathrm{L} / \mathrm{min})$, ventilation $(\mathrm{L} / \mathrm{min})$, breathing rate $\left(\mathrm{min}^{-1}\right)$, respiratory gasexchange ratios, and other parameters recorded every ten seconds. Exercise performance parameters consist of time to exhaustion (TE), total work ( $\left.\mathrm{W}_{\text {total }}\right)$, maximal power $\left(\mathrm{P}_{\max }\right)$, vertical distance, and horizontal distance computed by the treadmill's software considering the slope angle, speed and duration of each stage.

Each participant consumed one bottle of mineral water (500 ml) per day, containing $0.05 \mathrm{ml}$ peppermint essential oil for ten days. All the tests repeated after ten days of supplementation. Participants were asked to refrain from any medium to vigorous exercise and their diet was controlled during the study.

\section{Statistical analyses}

Normal distribution was tested using the KolmogorovSmirnov and Shapiro-Wilk tests. Paired t-test used to examine differences between pre-test and post-test. To calculate the magnitude of the difference between pretest and post-test, a Cohen's d calculated, using the following formula [18]:

$$
\text { Choen's d }=\frac{m_{1}-m_{2}}{\sqrt{\frac{\left(n_{1}-1\right) S D_{1}^{2}+\left(n_{2}-1\right) S D_{2}^{2}}{\left(n_{1}+n_{2}+2\right)}}}
$$

Cohen's d of 0.20 considered a minor, 0.50 a medium, and 0.80 a major difference. The statistical analysis performed using the Statistical Package for Social Sciences software (SPSS Version 16, SPSS Inc. Chicago, IL). 


\section{Results}

After ten days of supplementation with peppermint essential oil, the exercise performance evaluated by changes in the physiological parameters (spirometry and gas analysis) and functional indicators of exercise performance. The Kolmogorov-Smirnov and Shapiro-Wilks tests revealed the normality of the data. The parameters obtained from the gas analyzer during Bruce test presented in the Table 1.

Functional parameters significantly improved in posttest as compared with pre-test. A substantial increase in the respiratory ventilation, respiratory rate ( $\mathrm{RR}), \mathrm{VO}_{2} / \mathrm{Kg}$, $\mathrm{VCO}_{2} / \mathrm{Kg}, \mathrm{MET}$, and energy expenditure were observed showing enhancement in the respiratory efficiency and energy expenditure during the exercise. An increase in the breathing rate, normally leads to a lower alveolar and arterial $\mathrm{PCO}_{2}$ and therefore, decrease in the end-tidal carbon dioxide tension $\left(\mathrm{PETCO}_{2}\right)$ and fractional end-tidal $\mathrm{CO}_{2}$ concentration $\left(\mathrm{FETCO} \mathrm{C}_{2}\right)$ expected (Table 1).

Time to exhaustion, vertical distance, horizontal distance, maximum work, and power compared and presented in the Table 2.

Functional indicators of exercise performance showed significant increase in the time to exhaustion and distance (Table 2). In the Tables 3 and 4, the lung function indicators and other physiological parameters compared between pre-test and post-test.

Lung function tests significantly increased after ten days of supplementation. Peak inspiratory flow (PIF) shows maximum changes whereas forced vital capacity (FVC) had least changes and effect size.

Both resting and exercise heart rates were significantly decreased during post-test. Similarly, the chest circumference during maximum exhale and blood pressure in the post-test significantly decreased.

\section{Discussion}

Previous studies have shown that various kinds of mint were effective in reducing muscle pain $[19,20]$, muscle relaxation, and reduce fatigue [21]. However, previous studies showed inhaling peppermint aroma has no effect on the lung function tests and physical performance during acute and intensive exercise [18]. In a research on the effect of peppermint aroma during 15-minute low intensity treadmill exercise among male and female college students [22], no significant difference seen in the resting or exercise heart rate, oxygen consumption, ventilation, and perceived physical workload.

In the current research, improvement in the spirometric measurements (FVC, PEF, and PIF) and ventilation

Table 1 Physiological parameters obtained by gas analyser in Pre-test and Post-test

\begin{tabular}{|c|c|c|c|c|c|c|}
\hline Parameter & Pre-test $(n=12)$ & Post-test $(n=12)$ & Changes $\%$ & $\mathrm{~T}$ & $P$ value & Effect size \\
\hline $\mathrm{VO}_{2}[\mathrm{~L} / \mathrm{min}]$ & $2.74 \pm 0.40$ & $3.03 \pm 0.351$ & 10.5 & 6.757 & $p<0.001$ & 0.775 \\
\hline $\mathrm{VCO}_{2}[\mathrm{~L} / \mathrm{min}]$ & $3.08 \pm 0.47$ & $3.73 \pm 0.518$ & 21.1 & 5.594 & $p<0.001$ & 1.319 \\
\hline VE [L/min] & $84.60 \pm 17.74$ & $116.80 \pm 22.44$ & 38 & 4.790 & $p<0.001$ & 1.592 \\
\hline RR & $39.26 \pm 9.24$ & $50.53 \pm 7.33$ & 28.7 & 5.683 & $p<0.001$ & 1.352 \\
\hline $\mathrm{PETO}_{2}[\mathrm{mmHg}]$ & $88.87 \pm 4.19$ & $96.25 \pm 4.02$ & 8.3 & 5.869 & $p<0.001$ & 1.798 \\
\hline $\mathrm{PETCO}_{2}[\mathrm{mmHg}]$ & $40.86 \pm 4.28$ & $35.16 \pm 3.78$ & -16.2 & 7.270 & $p<0.001$ & 1.412 \\
\hline $\mathrm{DFCO}_{2} / \mathrm{DFO}_{2}$ & $1.109 \pm 0.053$ & $1.233 \pm 0.072$ & 7.4 & 4.233 & $p<0.005$ & 1.962 \\
\hline RER & $1.147 \pm 0.052$ & $1.247 \pm 0.066$ & 8.7 & 3.873 & $p<0.005$ & 1.690 \\
\hline $\mathrm{VO}_{2} / \mathrm{Kg}[\mathrm{ml} / \mathrm{kg} / \mathrm{min}]$ & $39.25 \pm 3.69$ & $43.63 \pm 3.78$ & 11.1 & 5.912 & $p<0.001$ & 1.174 \\
\hline $\mathrm{VCO}_{2} / \mathrm{Kg}[\mathrm{ml} / \mathrm{kg} / \mathrm{min}]$ & $44.95 \pm 4.61$ & $54.29 \pm 6.45$ & 20.7 & 4.769 & $p<0.005$ & 1.666 \\
\hline $\mathrm{VE} / \mathrm{Kg}[\mathrm{ml} / \mathrm{kg} / \mathrm{min}]$ & $1229.9 \pm 212.13$ & $1692.6 \pm 296.5$ & 37.6 & 4.306 & $p<0.005$ & 1.795 \\
\hline $\mathrm{EQO}_{2}$ & $30.60 \pm 4.65$ & $38.80 \pm 4.13$ & 26.7 & 4.984 & $p<0.001$ & 1.865 \\
\hline $\mathrm{EQCO}_{2}$ & $26.20 \pm 3.65$ & $31.20 \pm 2.78$ & 19 & 6.578 & $p<0.001$ & 1.542 \\
\hline VT [L] & $2.165 \pm 0.489$ & $2.536 \pm 0.404$ & 17.1 & 6.770 & $p<0.001$ & 0.827 \\
\hline VA [L] & $86.00 \pm 19.22$ & $117.31 \pm 22.22$ & 36.4 & 4.492 & $p<0.005$ & 1.507 \\
\hline METS & $11.21 \pm 1.06$ & $12.48 \pm 1.07$ & 11.3 & 6.054 & $p<0.001$ & 1.192 \\
\hline $\mathrm{EE}[\mathrm{kcal} / \mathrm{h}]$ & $847.60 \pm 123.64$ & $955.10 \pm 116.98$ & 12.6 & 6.138 & $p<0.001$ & 0.893 \\
\hline $\mathrm{FETO}_{2}[\%]$ & $14.95 \pm 0.70$ & $16.35 \pm 0.55$ & 9.3 & 6.917 & $p<0.001$ & 2.232 \\
\hline $\mathrm{FETCO}_{2}[\%]$ & $6.681 \pm 0.679$ & $5.800 \pm 0.507$ & -15.1 & 6.102 & $p<0.001$ & 1.470 \\
\hline $\mathrm{CHO}[\mathrm{kcal} / \mathrm{h}]$ & $1276.7 \pm 232.39$ & $1721.4 \pm 327.85$ & 34.8 & 4.170 & $p<0.005$ & 1.565 \\
\hline FAT [kcal/h] & $323.38 \pm 124.04$ & $691.06 \pm 223.77$ & 13.6 & 4.834 & $p<0.001$ & 2.032 \\
\hline
\end{tabular}

Data are expressed as mean \pm SD. 
Table 2 Changes in the exercise performance parameters

\begin{tabular}{|c|c|c|c|c|c|c|}
\hline Parameter & Pre-test $(n=12)$ & Post-test $(n=12)$ & Changes $\%$ & $\mathrm{~T}$ & $P$ value & Effect size \\
\hline Horizontal distance $(\mathrm{m})$ & $843.5 \pm 234.6$ & $1187.6 \pm 309.2$ & 40.7 & 6.890 & $p<0.001$ & 1.254 \\
\hline Vertical distance $(m)$ & $113.4 \pm 40.09$ & $172.8 \pm 59.41$ & 52.3 & 6.262 & $p<0.001$ & 1.173 \\
\hline Work (KJ) & $78.34 \pm 32.84$ & $118.7 \pm 47.38$ & 51.5 & 5.746 & $p<0.001$ & 0.992 \\
\hline Power (KW) & $114.3 \pm 24.24$ & $139.4 \pm 27.80$ & 21.9 & 6.764 & $p<0.001$ & 0.962 \\
\hline Time to exhaustion (S) & $664.5 \pm 114.2$ & $830.2 \pm 129.8$ & 24.9 & 7.255 & $p<0.001$ & 1.355 \\
\hline
\end{tabular}

Data are expressed as mean $\pm S D$.

during treadmill exercise, as well as an increase in the maximum chest circumferences observed. These results can be justified by decreasing the airway and bronchial smooth muscle tonicity with or without effect on the pulmonary surfactant. Previously, reported a significant increase in the respiratory muscle strength after fourweek inspiratory and expiratory muscle training on the respiratory muscle strength and time to exhaustion in healthy people [15]. In the current study, PIF, which is dependent on strength and speed of shortening of the inspiratory muscles, significantly improved. Therefore, an increase in the inspiratory muscle strength after peppermint consumption is conceivable.

In an in-vitro study, menthol vapour lowered the surface tension on synthetic surfactant films [23]. It may change the lung surface tension and its function [23]. Bronchodilatory effect of peppermint is unlikely because previous research [24] investigated the effect of salbutamol as a $\beta_{2}$-adrenergic receptor agonist and with bronchodilator effect on the cycling performance. However, there was no significant difference in any variables related to aerobic endurance or cycling performance [24]. In yet another four-week randomised placebo controlled study, 23 subjects with chronic mild asthma received either nebulised menthol $(10 \mathrm{mg}$ twice a day) or placebo. No effect on the forced expiratory volume reported in the experimental group. However, the menthol group significantly decreased their bronchodilator medicines and had fewer wheezing episodes [15]. It can be speculated that oral supplementation in the current study is preferred to longer time nebulised menthol administration. We suggest further investigations on the hepatic metabolism of the peppermint essential oil components to elucidate the pharmacokinetics of peppermint absorbed through the nose, mouth or intestine.
The result of the current study supports the theory that delaying fatigue may be related to physiological changes by decreasing blood lactate level similar to the recent finding [25]. Furthermore, significant increase in the carbohydrate metabolism after ten days of supplementation (Table 1) is implying that peppermint can improve the muscular energy metabolism. Further studies are needed to elucidate the possible effects of peppermint in the cellular energy metabolism.

The stimulating effect of peppermint on the CNS [11] may also be responsible. Extensive research on the effectiveness of aromas on cognitive performance, perceived physical workload, and pain responses were conducted based on possible changes in the brain activity $[3,7,16,18,22,26-28]$.

Table 1 demonstrated significant changes in the gas analysis results after ten days of supplementation with peppermint essential oil. In the supplementation phase, subjects kept their physical activity in minimum level, therefore; plausible explanation would be a positive effect of supplementation on the cardiovascular and respiratory efficiency. Positive changes in carbohydrate and fat oxidation in accordance with enhancement of energy expenditure and MET may be related to some unknown effects on the cellular level. Although reported that peppermint may accentuate energy by stimulating the adrenal cortex [29], it is unclear what dosage and how this increased energy may affect the exercise performance. In other studies [22,28], aroma had no significant effects on the oxygen consumption in both lowintensity 15-minute treadmill task and sub-maximal treadmill running test.

It seems peppermint has a lowering effect on the heart rate and the systolic blood pressure. Reduction in the arterial smooth muscle tonicity is a possible explanation for these effects. One study administered peppermint

Table 3 Spirometry parameters in the Pre-test and Post-test

\begin{tabular}{lcccccc}
\hline Parameter & Pre-test $(\mathbf{n}=\mathbf{1 2})$ & Post-test $(\mathbf{n}=\mathbf{1 2})$ & Changes\% & T & P value & Effect size \\
\hline FVC (L) & $4.57 \pm 0.90$ & $4.79 \pm 0.84$ & 4.8 & 6.336 & $\mathrm{p}<0.001$ & 0.258 \\
PEF (L/s) & $8.50 \pm 0.94$ & $8.87 \pm 0.92$ & 4.35 & 3.446 & $\mathrm{p}<0.01$ & 0.401 \\
PIF (L/s) & $5.71 \pm 1.16$ & $6.58 \pm 1.08$ & 15.1 & 4.505 & $\mathrm{p}<0.005$ & 0.776 \\
\hline
\end{tabular}

Data are expressed as mean \pm SD. 
Table 4 Cardiopulmonary parameters obtained from the Pre-test and Post-test

\begin{tabular}{|c|c|c|c|c|c|c|}
\hline Parameter & Pre-test $(n=12)$ & Post-test $(n=12)$ & Changes $\%$ & $\mathrm{~T}$ & $P$ value & Effect size \\
\hline Resting heart rate & $65.18 \pm 12.72$ & $62.18 \pm 11.82$ & -4.8 & 3.609 & $p<0.005$ & 0.244 \\
\hline Maximum heart rate & $173.4 \pm 14.35$ & $187.4 \pm 15.17$ & 8 & 3.777 & $p<0.005$ & 0.954 \\
\hline Systolic blood pressure & $11.99 \pm 0.87$ & $11.28 \pm 0.85$ & -6.2 & 5.440 & $p<0.001$ & 0.824 \\
\hline Diastolic blood pressure & $6.645 \pm 0.503$ & $6.164 \pm 0.566$ & -7.8 & 7.831 & $p<0.001$ & 0.900 \\
\hline Chest circumference at max. inhale & $89.41 \pm 4.59$ & $89.95 \pm 4.66$ & 0.6 & 2.782 & $p<0.05$ & 0.118 \\
\hline Chest circumference at max. exhale & $83.73 \pm 5.28$ & $82.41 \pm 5.14$ & -1.6 & 4.342 & $p<0.005$ & 0.253 \\
\hline
\end{tabular}

Data are expressed as mean \pm SD.

aroma by nose and failed to find any significant effect in both heart rate and blood pressure. The differences in the peppermint essential oil method of administration and supplementation period, can justify the effectiveness of peppermint in the current study.

\section{Conclusions}

To our knowledge, this is the first study that explored the effect of oral supplementation with peppermint essential oil on the exercise performance. Our results strongly support the effectiveness of peppermint essential oil on the exercise performance, respiratory function variables, systolic blood pressure, heart rate, and respiratory gas exchange parameters. Differences in duration of study and oral supplementation instead of inhalation of peppermint aroma could be the important characteristics of this study compare to the previous researches. Further investigations are required to unravel the mechanism underlying the effectiveness of peppermint on the exercise performance and respiratory parameters.

\section{Abbreviations}

FVC: Forced vital capacity; PEF: Peak expiratory flow rate; PIF: Peak inspiratory flow; $W_{\text {total }}$ : Calculated total work; $P_{\text {max }}$ : Maximal power output; CNS: Central nervous system; $\mathrm{VO}_{2}$ : Oxygen uptake; $\mathrm{VCO}_{2}$ : Carbon dioxide elimination: VE: Minute ventilation; RR: Respiratory rate; $\mathrm{PETO}_{2}$ : End-tidal oxygen tension; $\mathrm{PETCO}_{2}$ : End-tidal carbon dioxide tension; RER: Respiratory exchange ratio; EQO2: Ventilatory equivalents for $\mathrm{O}_{2}$; $\mathrm{EQCO}_{2}$ : Ventilatory equivalents for $\mathrm{CO}_{2}$; VT: Tidal volume; VA: Alveolar ventilation; METS: Metabolic equivalent; EE: Energy expenditure; $\mathrm{FETO}_{2}$ : Fractional end-tidal $\mathrm{O}_{2}$ concentration; $\mathrm{FETCO}_{2}$ : Fractional end-tidal $\mathrm{CO}_{2}$ concentration; $\mathrm{CHO}$ : Carbohydrate.

\section{Competing interests}

Authors of this paper have not received any financial remuneration for preparing this paper. The authors declare that they have no competing interests.

\section{Authors' contributions}

The authors' responsibilities were as follows-A.M. is responsible for research design, conducting laboratory tests, statistical analysis and manuscript preparation. A.R. was responsible for subject recruitment and laboratory tests assistance. Both authors read and approved the final manuscript.

\section{Authors' information}

Dr. Abbas Meamarbashi is Associate Professor and Head of the Department of Physical Education and Sport Science at the University of Mohaghegh Ardabili. He has been published in many peer-reviewed journals. Sport nutrition is one of his fields of interest. Mr. Ali Rajabi is an MSc student in sport physiology.

\section{Acknowledgments}

We gratefully acknowledge the enthusiastic support of the subjects who volunteered to participate in this study. No external funding was provided for this study.

Received: 22 February 2012 Accepted: 7 March 2013

Published: 21 March 2013

\section{References}

1. Almeida RN, Hiruma CA, Barbosa-Filho JM: Analgesic effect of rotundefolone in rodents. Fitoterapia 1996, 67:334-338.

2. Della Loggia R, Tubaro A, Lunder T: Evaluation of some pharmacological activities of a peppermint extract. Fitoterapia 1990, 61:15-221.

3. Raya MD, Utrilla MP, Navarro MC, Jimenez J: CNS activity of Mentha rotundifolia and Mentha longifolia essential oil in mice and rats. Phytother Res 1990, 4:232-234.

4. Mimica-Dukić N, Božin B, Soković M, Mihajlović B, Matavulj M: Antimicrobial and antioxidant activities of three Mentha species essential oils. Planta Med 2003, 69:413-419.

5. Ahijevych K, Garrett BE: Menthol pharmacology and its potential impact on cigarette smoking behavior. Nicotine Tob Res 2004, 6:S17-S28.

6. Mauskop A: Alternative therapies in headache: is there a role? Medical Clinics of North America 2001, 85:1077-1084.

7. Raudenbush B, Koon J, Meyer B, Flower N: Effects of ambient odor on pain threshold, pain tolerance, mood, workload, and anxiety. In Second Annual Meeting of the Society for Psychophysiological Research. Washington DC: Society for Psychophysiological Research; 2002.

8. Zoladz P, Raudenbush B, Lilley S: Cinnamon perks performance, Paper presented at the The $31^{\text {st }}$ annual Association for Chemoreception Sciences meeting, Sarasota, FL, USA. 2009.

9. Barker S, Grayhem P, Koon J, Perkins J, Whalen A, Raudenbush B: Improved performance on clerical tasks associated with administration of peppermint odor. Percept Mot Ski 2003, 97:1007-1010.

10. Raudenbush B, Meyer B, Eppich W: Effects of odor administration on objective and subjective measures of athletic performance. International Sports Journal 2002, 6:1-15.

11. Umezu T, Sakata A, Ito $\mathrm{H}$ : Ambulation-promoting effect of peppermint oil and identification of its active constituents. Pharmacol Biochem Behav 2001, 69:383-339.

12. Sönmez GT, M Ç, Sönmez S, Schoenfeld B: Effects of oral supplementation of mint extract on muscle pain and blood lactate. Biomedical Human Kinetics 2010, 2:66-69.

13. Göbel H, Schmidt G, Soyka D: Effect of peppermint and eucalyptus oil preparations on neurophysiological and experimental algesimetric headache parameters. Cephalalgia 1994, 14:228-234.

14. Raudenbush B, Zoladz P: The effects of peppermint odor administration on lung capacity and inhalation ability. Washington: Seattle; 2003.

15. Tamaoki J, Chiyotani A, Sakai A, Takemura H, Konno K: Effect of menthol vapour on airway hyperresponsiveness in patients with mild asthma. Respir Med 1995, 89:503-504.

16. Raudenbush B, Corley N, Eppich W: Enhancing athletic performance through the administration of peppermint odor. J Sport Exerc Psychol 2001, 23:156-160.

17. Vickers A: Yes, but how do we know it's true? Knowledge claims in massage and aromatherapy. Complement Ther Nurs Midwifery 1997, 3:63-65. 
18. Pournemati P, Azarbayjani MA, Rezaee MB, Ziaee V: The effect of inhaling peppermint odor and ethanol in women athletes. Bratisl Lek Listy 2009, 10:782-787

19. Mimica-Dukic N, Jakovljevic V, Sabo A, Popovic M, Lukic V, Gasic O, Jancic R: Evaluation of some pharmacodynamic effects of Mentha longifolia extracts. Planta Med 1993, 59:691.

20. Forster HB, Niklas H, Lutz S: Antipasmodic effects of some medicinal plants. Planta Med 1981, 40:309-319.

21. Genders R: The Complete Book of Herbs and Herb Growing. London: Ward Lock Limited; 1988

22. Simpson WF, Coady RC, Osowski EE, Bode DS: The effect of aromatherapy on exercise performance. Kinesiology On-Line 2001, 9(22). Retrieved from http://www.iowaahperd.org/journal/simpson.html\#simpson.

23. Zänker KS, Tölle W, Blümel G, Probst J: Evaluation of surfactant-like effects of commonly used remedies for colds. Respiration 1980, 39:150-157.

24. Norris SR, Petersen SR, Jones RL: The effect of salbutamol on performance in endurance cyclists. European Journal Of Applied Physiology And Occupational Physiology 1996, 73:364-368.

25. Powers S, Howley E: Exercise Physiology: Theory and Application to Fitness and Performance. New York: Mc Graw Hill; 2009.

26. Raudenbush B, Smith J, Graham K, McCune A: Effects of peppermint odor administration on augmenting basketball performance during game play. Chem Senses 2005, 30:265-278.

27. Buchbauer G, Jirovetz L, Jager W, Dietrich H, Plank C, Singh SP, Walsh LJ, Longstaff J, Naples JM, Shiff CJ: Aromatherapy: evidence for sedative effects of the essential oil of lavender after inhalation. Z Naturforsch C 1991, 30:395-396.

28. Raudenbush B: The effects of odors on objective and subjective measures of physical performance. The Aroma-Chology Review 2000, 9:1-5.

29. Burton Goldberg G: Alternative Medicine: The Definitive Guide. 2nd edition. Puyallup, WA: Future Medicine Pub; 1993.

doi:10.1186/1550-2783-10-15

Cite this article as: Meamarbashi and Rajabi: The effects of peppermint on exercise performance. Journal of the International Society of Sports Nutrition 2013 10:15.

\section{Submit your next manuscript to BioMed Central and take full advantage of:}

- Convenient online submission

- Thorough peer review

- No space constraints or color figure charges

- Immediate publication on acceptance

- Inclusion in PubMed, CAS, Scopus and Google Scholar

- Research which is freely available for redistribution 